\title{
Zur quantitativen Bestimmung der freien Salzsäure im Magensafte
}

\author{
von \\ Prof. Dr. R. v. Jaksch in Graz. \\ (Vorgelegt in der Sitzung am 23. Mai 1889.)
}

Sjöqvist ${ }^{1}$ hat jüngst, einer Idee von Mörner folgend, eine Methode angegeben, mittels der es rasch gelingt, die im Magen, safte sich findende, freie Salzsäure quantitativ za bestimmen. Die Methode besteht im Wesentlichen darin, dass durch Überführung der vorhandenen, freien Säuren in ibre Barytsalze, durch Verbrennung der organischen Barytsalze zu kohlensaurem Baryt und durch Extraction mit Wasser Chlorbarium in Lösung gehtdas durch Titriren mit doppelt chromsaurem Kalium quantitativ bestimmt wird. So werthvoll diese Methode ist, so schien sie mir doch einiger Verbesserungen fähig, und insbesondere war es für meine an einem anderen Orte ausführlich zu beschreibenden Untersuchungen nothwendig, eine Methode zu besitzen, mittels der es genauer als durch die Titrirmethode gelingt, kleine Mengen freier Salzsäure im Magensafte mit Sicherheit zu bestimmen. Die Methode, der ich mich bediente, ist im Wesentlichen die, welche Sjöqrist angegeben hat, mit dem Unterschiede, dass die vorhandene freie Salzsäure als schwefelsaurer Baryt gewogen wird.

Die Ausführung der Bestimmungen erfolgte in nachstehender Weise : $10 \mathrm{~cm}^{3}$ der Versuchsflissigkeit, respective des Magensaftes wurden mit einem Tropfen neutraler Lakmustinctur versetzt, und absolut chlorfreier, kohlensaurer Baryt hinzugefügt, bis das Gemenge nicht mehr roth gefärbt erschien. Dann bringt man das-

1 Sjöqvist, Zeitschr. für physiolog. Chemie 13, 1, 1889. 
selbe in einer Platin- oder Nickelschale auf ein Wasserbad und dampft unter dem Herde bei sorgfältigem Abschlusse aller Salzsäuredämpfe zur Staubtrockene ein.

Nach dem Eindampfen wird die Scbale allmählig erhitzt, bis die organische Substanz verbrannt ist, und nach dem Abkïhlen wiederholt mit heissem Wasser extrahirt und filtrirt. Die Menge des klaren Filtrates soll 80 bis $100 \mathrm{~cm}^{3}$ nicht ïberschreiten. In dem Filtrate wird das darin enthaltene Chlorbarium als schwefelsaurer Baryt bestimmt.

Bei exacter Durchfiihrung gibt dieses Vorgehen brauchbare Resultate, wie die folgenden Beleganalysen ergeben. Zu diesem Zwecke stellte ich mir Gemenge her, welche neben wechselnden Mengen von kochsalzhältigen Pepton $(0.01-0.0003 g)$ und wechselnden Mengen von freier Milchsäure, Essigsäure und Buttersäure $(0.05-0.0025 \mathrm{~g}$ jeder der obengenannten Säuren) wechselnde Mengen freier Salzsäure enthielten. Die Substanzen waren in $1 \cdot 6-23 \mathrm{~cm}^{3}$ Wasser enthalten. Zehn Versuche ergaben folgende Zahlen:

$\begin{array}{rlc}\text { I. } 0.0871 g \text { Salzsäure, gefunden: } & 0.0853 g & \text { Differenz } \\ \text { II. } 0.0522 & 0.0526 & +0.0018 g \\ \text { III. } 0.0174 & 0.0156 & -0.0004 \\ \text { IV. } 0.0104 & 0.0096 & -0.0008 \\ \text { V. } 0.0035 & 0.0031 & -0.0004 \\ \text { VI. } 0.0017 & 0.00095 & -0.00075 \\ \text { VII. } 0.0017 & 0.0011 & -0.0006 \\ \text { VIII. } 0.0009 & 0.0003 & -0.0006 \\ \text { IX. } 0.0009 & 0.0001 & -0.0008 \\ \text { X. } 0.0009 & 0.0004 & -0.0005\end{array}$

Es lassen sich also noch mehrere Milligramm Salzsäure mit ziemlicher Sicherheit bestimmen, unter diesem Werthe wird die Bestimmung ungenau und treten im Verhältnisse zu der Menge der vorbandenen Salzsäure grosse Differenzen auf. In keinem Versuche überschritt die Differenz zwischen der vorhandenen und gefundenenen Menge Salzsäure 0.0018 $\mathrm{g}$.

Damit aber die oben angeführten, genauen Resultate erhalten werden, ist es unerlässlich, dass

1. Alle Operationen in einem von Salzsäuredämpfen möglichst freien Raume ansgeführt werden. 
2. Das Eindampfen und Verbrennen nicht - wie ich es selbst anfangs that - in der Muffel ausgefuhrt wird, indem die geringen Mengen von Salzsäuregas, welche in der Laboratoriumsluft enthalten sind und die mit der Flamme über die Schale längere Zeit streichen, das Resultat ungenau machen, d. h. die Totalmenge der Salzsäure erhöhen.

3. Ein zu grosser Überschuss von Baryt vermieden wird.

4. Der zu diesen Versuchen verwendete Baryt absolut ehlorfrei ist.

Ich füge ausdrücklich hinzu, dass ich die Nothwendigkeit -dieser Bedingungen, von denen nur die letzte von vornherein selbstverständlich erscheint, durch eine Reihe von Bestimmungen als absolut nothwendig kennen gelernt habe.

Eine Reihe von Versuchen (circa 50 Bestimmungen), welche ich in der oben skizzirten Weise mit dem Magensafte des Kindes ausgeführt habe, gaben mir Aufschluss über den zeitlichen Verlauf der Salzsäuresecretion. Ich werde demnächst an einem anderen Orte über dieselben berichten.

Wenn ich diese Methode, welche chemisch nichts neues bietet, veröffentliche, so hat dies darin seinen Grund, dass sie bei. ihrer Handlichkeit und bei den exacten Resultaten, welche sie erzielt, anch in der Hand des Physiologen zur Bestimmung der freien Salzsäure unter den verschiedensten Bedingungen sich bewähren dürfte, wie ich bei der Untersuchung anderer Secrete bereits erfahren habe. 